\title{
Primary cutaneous apocrine carcinoma arising within a congenital nevus: Keratins and filaggrin expression suggesting differentiation into the secretory cells of apocrine glands
}

\author{
YUKO SENBA $^{1}$, ICHIRO KUROKAWA ${ }^{1}$, KAZUYA TOKIME ${ }^{1}$, KOJI HABE ${ }^{1}$, KEN-ICHI ISODA ${ }^{1}$, \\ KEI-ICHI YAMANAKA ${ }^{1}$, AIRO TSUBURA ${ }^{2}$ and HITOSHI MIZUTANI ${ }^{1}$ \\ ${ }^{1}$ Department of Dermatology, Mie University Graduate School of Medicine, Tsu, Mie 514-8507; \\ ${ }^{2}$ Department of Pathology, Kansai Medical University, Moriguchi, Osaka 570-8506, Japan
}

Received January 7, 2010; Accepted March 9, 2010

DOI: 10.3892/ol_00000072

\begin{abstract}
Primary cutaneous apocrine carcinoma (PCAC) is a rare neoplasm of skin appendages. To determine the differentiation of apocrine carcinoma, we studied the expression of epithelial keratins and filaggrin immunohistochemically using 10 anti-keratin antibodies againt keratin $(\mathrm{K}) 1,7,8,10$, $14,15,16,17,18,19$ and the anti-filaggrin antibody. PCAC demonstrated strong positivity for K7, K8, K18 and K19. These keratins are distributed in secretory cells of normal apocrine glands. The tumor cells were negative for K14 and K17. The two keratins exist in myoepithelial cells in normal apocrine glands. Results suggest that PCAC shows differentiation into secretory cells of apocrine glands, although it does not differentiate into myoepithelial cells. K14 is also known as undifferentiated keratin, whereas K17 is considered to be a hyperproliferative keratin. Absence of the expression of K14 and K17 may reflect an indolent clinical course of PCAC.
\end{abstract}

\section{Introduction}

Primary cutaneous apocrine carcinoma (PCAC) is a rare skin neoplasm. Although approximately 40 cases of PCAC have been reported (1), no previous reports regarding apocrine carcinoma within a congenital melanocytic nevus exist.

The origin of PCAC remains unclear. Keratin $(\mathrm{K})$ is an essential marker of epithelial neoplasms used to evaluate the origin of the tumor and stage of differentiation $(2,3)$. Filamentaggregating protein (filaggrin) is a marker of terminal epidermal differentiation (4). To elucidate the differentiation of PCAC, we studied the expression of epithelial keratin and filaggrin in PCAC using 10 anti-keratin antibodies and an anti-filaggrin antibody. Immunohistochemical studies of PCAC using types

Correspondence to: Dr Yuko Senba, Department of Dermatology, Mie University Graduate School of Medicine, 2-174 Edobashi, Tsu, Mie 514-8507, Japan

E-mail: senba-y@clin.medic.mie-u.ac.jp

Key words: apocrine carcinoma, apocrine, keratin, filaggrin, nevus of anti-keratin antibodies that identify multiple keratins exist (5). However, this is the first systematic study to investigate PCAC with detailed immunohistochemistry results using monospecific anti-keratin antibodies and an anti-filaggrin antibody.

\section{Materials and methods}

A 70-year-old male presented to our hospital with a 10-year history of a slow-growing, red-to-black nodule that developed into a large black macule on his back. He had a pigmented macule on his back at birth that had been treated 50 years earlier with cryotherapy using liquid nitrogen. A clinical examination showed a leaf-shaped black macule measuring $22 \times 10.5 \mathrm{~cm}$ on the patient's back. On the left side of the macule, a 45x30 mm in diameter red-to-black nodule with ulceration was observed (Fig. 1). The left axillary lymph node was palpable. No other occult carcinomas, including breast carcinoma, were detected. The macule, including the tumor, was totally excised and a left axillary lymphadenectomy was performed. Each specimen was fixed in formalin, embedded in paraffin and stained with hematoxylin and eosin. Serially cut sections were used in the immunohistochemical study. Informed consent was obtained from the patient before the treatment.

An immunohistochemical study of gross cystic disease fluid protein 15 (GCDFP-15), s100a and HMB-45 was performed. The epithelial keratin and filaggrin expression was also studied using immunohistochemical procedures. The anti-keratin and anti-filaggrin antibodies used in this study were: 34ßB4 (K1) (6), LP5K (K7) (7), LP3K (K8) (7), HP1 (K10) (8), LL002 (K14) (7), LHK15 (K15) (9), LL025 (K16) (7), E3 (K17) (7), 5D3 (K18) (7), b170 (K19) (10) and $15 \mathrm{C} 10$ (filaggrin) (4) (all from Novocastra Laboratories Ltd., Newcastle upon Tyne, UK). This immunohistochemical study employed the labeled streptoavidin-biotin method (LSAB; Dako, Carpinteria, CA, USA) as previously reported (11). Normal skin from the scalp was used for control specimens.

\section{Results}

Hematoxylin and eosin staining. Including ulceration, the tumor occupied the dermis and the upper subcutaneous fatty 
tissue (Fig. 2A). There was a complex glandular arrangement including tubular, solid and cord-like areas. In the upper dermis, large lumina with decapitation secretion were observed, whereas invasive growth of smaller tumor nests in the surrounding tissue was noted in the subcutaneous fat. The neoplastic cells had abundant eosinophilic granular cytoplasm and atypical round, hyperchromatic nuclei with prominent nucleoli (Fig. 2B). Mitotic figures were occasionally seen. The histopathological diagnosis was apocrine carcinoma, due to the characteristic 'apocrine snout'. According to the subclassification of PCAC by Ackerman et al (12), the tumor was classified into cutaneous apocrine ductal carcinoma. Metastasis was observed to the left axillary lymph nodes.

Around the tumor and in the stroma between the tumor nests, dense diffuse proliferation of small monomorphous melanocytes without atypia was observed (Fig. 2C). The melanocytes demonstrated an adnexocentric or angiocentric arrangement and were disposed in single files between collagen bundles. These histopathological features were consistent with congenital melanocytic nevus. Within the nevus, ectopic apocrine glands, which were larger glands without nuclear atypia showing decapitation secretion, were located adjacent to the tumor (Fig. 2D). Benign apocrine neoplasm was not found. Neither sebaceous hyperplasia nor follicular anomaly, frequently noted in nevus sebaceous of Jadasshon, was observed. We therefore considered this case to be an apocrine carcinoma developed within a congenital melanocytic nevus.

Immunohistochemical findings. The tumor cells were positive for GCDFP-15 and negative for s100a and HMB-45. Table I shows the pattern of keratin and filaggrin expression in the normal

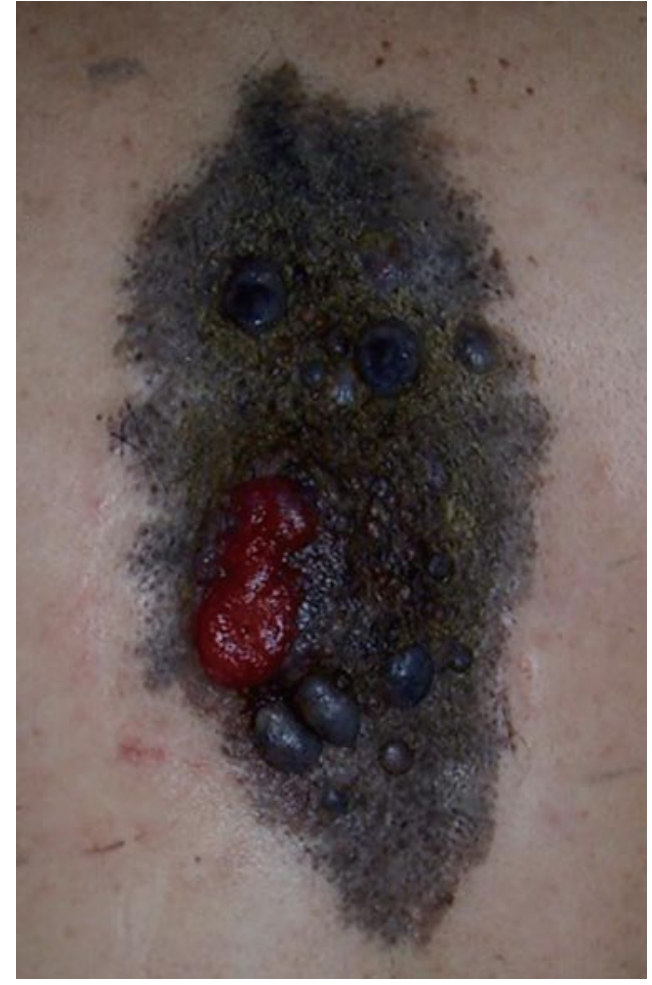

Figure 1. A red-to-black nodule that developed into a large black macule on the back.

apocrine glands and tumor. The tumor demonstrated a diffuse strong positivity for K7, 8, 18 and 19 (Figs. 3A-C). Tumor cells were negative for $\mathrm{K} 1,14,15,16$ and 17 . K10 was focally distributed in ductal structures within the tumor (Fig. 3D).
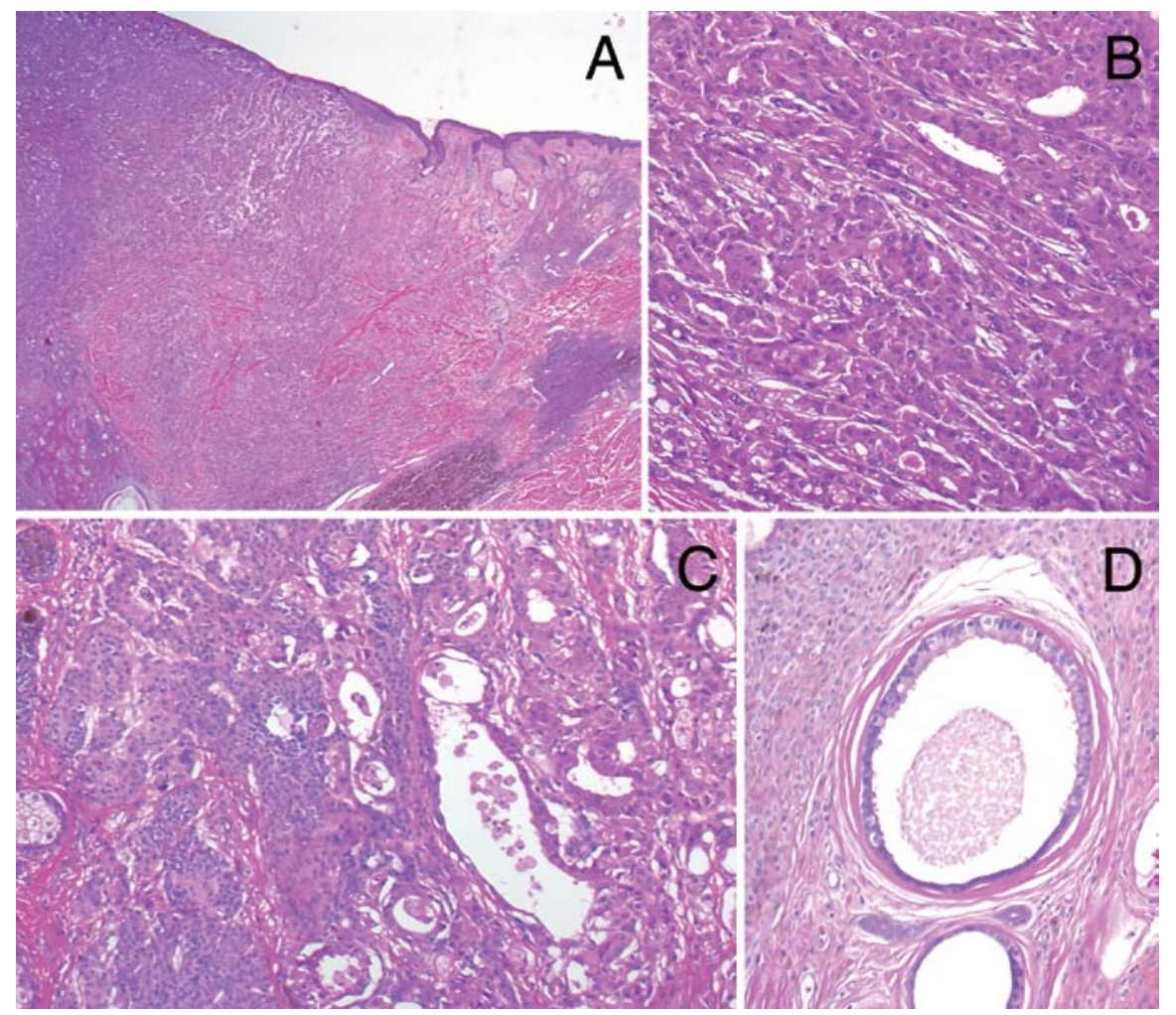

Figure 2. Hematoxylin and eosin staining. (A) Apocrine carcinoma occupying the dermis, showing invasive growth in the surrounding congenital melanocytic nevus. (B) Tubular structures showing decapitation secretion consisted of tumor cells with abundant eosinophilic granular cytoplasm and round, hyperchromatic nuclei. (C) Apocrine carcinoma adjacent to the nests of melanocytes. (D) Ectopic apocrine glands within a congenital melanocytic nevus. 


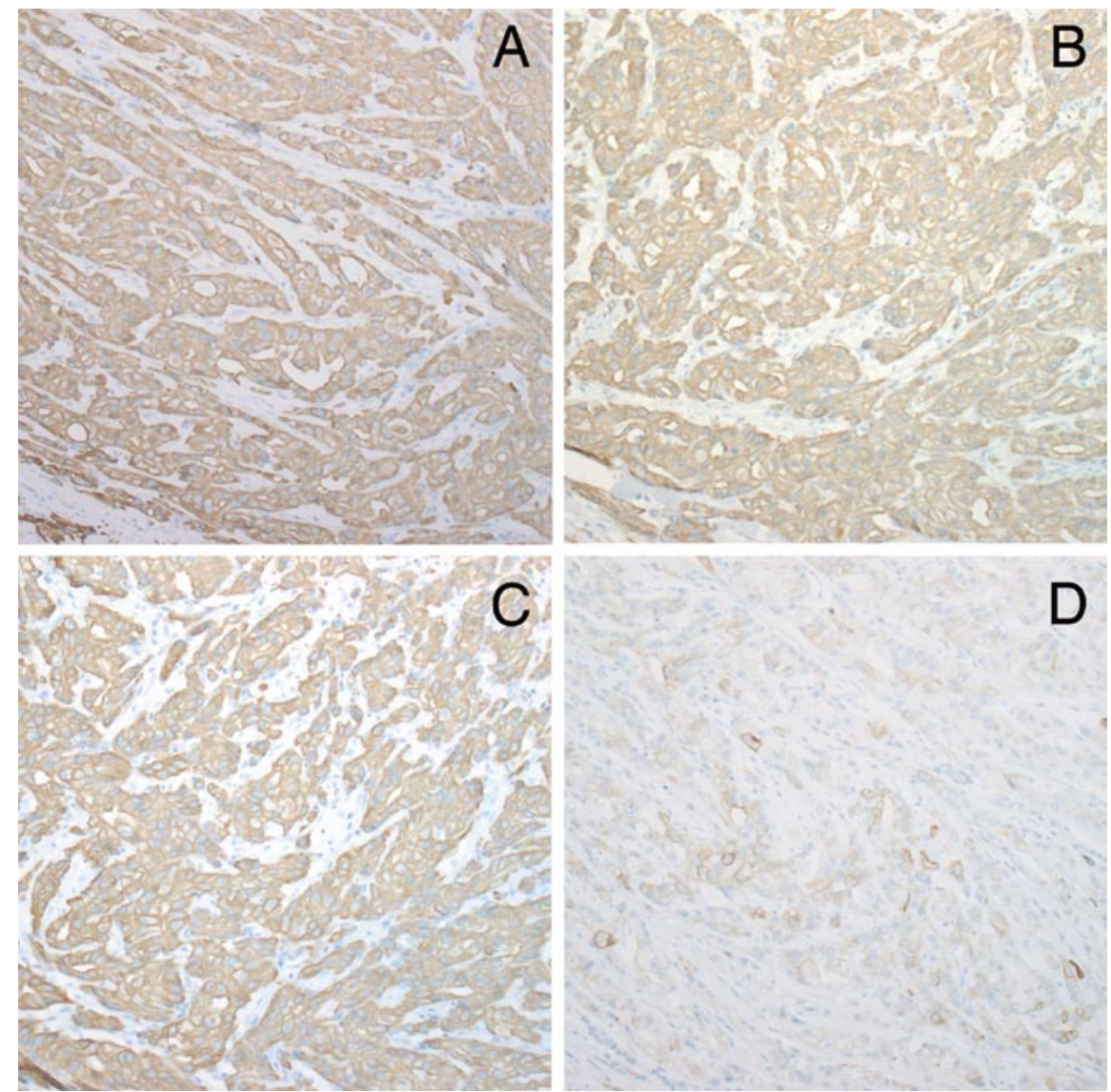

Figure 3. Immunohistochemistry of keratins (K). The tumor showed a diffuse strong positivity for (A) K7, (B) K8, (C) K18 and K19, and focal positivity for (D) K10.

Table I. Keratin expression in the normal apocrine gland and carcinoma.

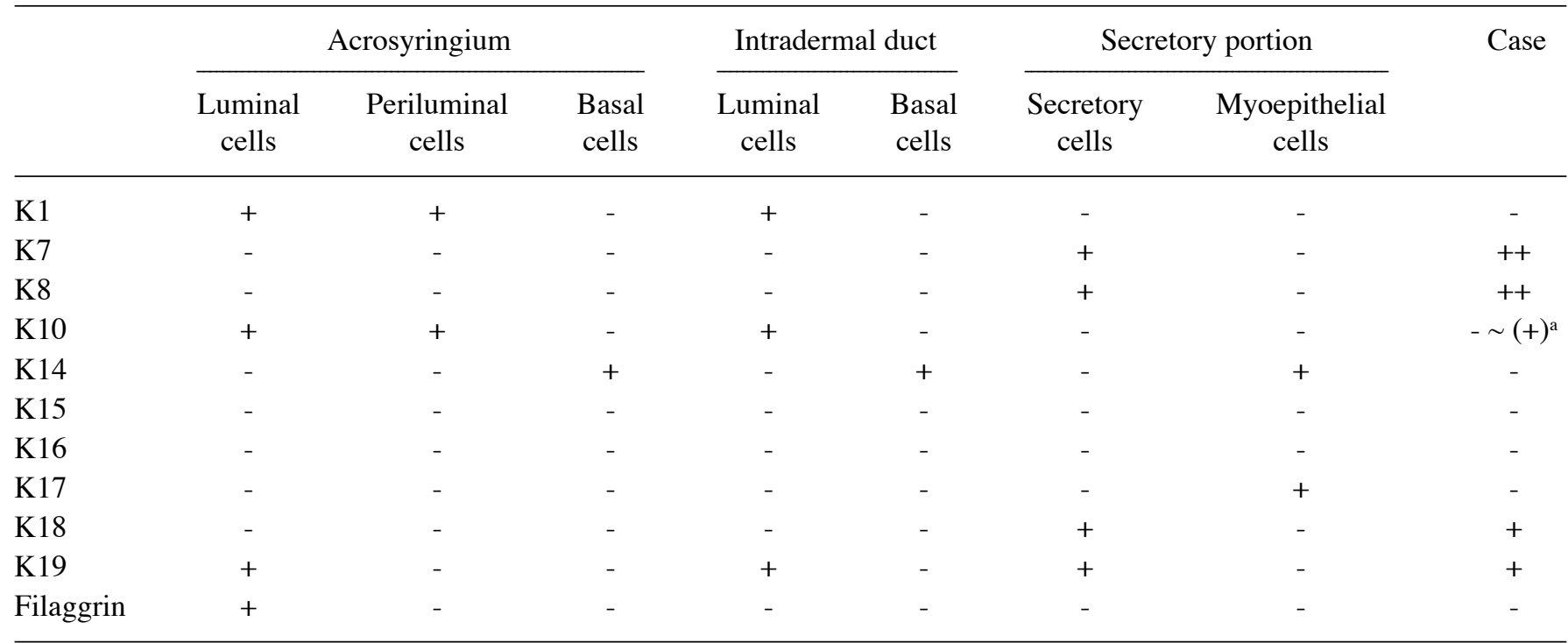

${ }^{a}$ Focal expression of $\mathrm{K} 10$ in ductal structure within the tumor was observed.

\section{Discussion}

Primary cutaneous apocrine carcinomas (PCAC) are rare neoplasms and have yet to be fully investigated. Approximately 40 cases of PCAC have been reported (1). The majority of
PCACs are relatively indolent, but some are rapidly progressive (13). The prognosis of PCAC is generally favorable and depends on the degree of tumor differentiation. PCAC appears where normal apocrine glands exist including axilla, eyelid, anogenital lesions, but rarely the chest and lip $(14,15)$. 
PCAC occasionally arises from ectopic apocrine glands in nevus sebaceous $(16,17)$ or from benign apocrine neoplasms such as tubular apocrine adenoma $(18,19)$, cylindroma $(20)$ and spiradenoma (21). PCAC was located overlying a large congenital melanocytic nevus in our case. To the best of our knowledge, no reports of PCAC on the congenital melanocytic nevus or other melanocytic nevi have been reported. Since ectopic apocrine glands were observed within the nevus, we suggested that, in our study, PCAC originated from these ectopic apocrine glands.

The pattern of keratin and filaggrin expression in normal apocrine glands is summarized in Table I $(11,22,23)$. In acrosyringium and dermal duct, luminal cells showed positivity for K1, 10 and 19, whereas basal cells were positive for K14. In the secretory portion of the apocrine gland, secretory cells expressed K7, 8, 18 and 19, whereas myoepithelial cells expressed K14 and 17. Keratin expression is unique in each section of the normal apocrine sweat gland (luminal cells and basal cells of the acrosyringium and intradermal duct, secretory cells and myoepithelial cells of the secretory portion) Thus, the origin of PCAC was determined according to the pattern of keratin distribution.

The keratin profile of PCAC in our case is shown in Table I. K7, K8, K18 and K19 were detected in the tumor as well as in secretory cells in the normal apocrine gland. We therefore speculated that PCAC differentiated into the secretory cells in the apocrine glands. Focal expression of K10 in the ductal structure within the tumor nests showed that some PCAC exhibited differentiation into the apocrine dermal duct. On the other hand, the tumor nests did not express K14 and 17 since these keratins are normally distributed in myoepithelial cells in the secretory portion of apocrine glands. This finding suggests that PCAC is composed not of a proliferation of myoepithelial cells but of secretory cells. PCAC did not express K14, 16 or 17. K14, a basal keratin, is undifferentiated, whereas K16 and 17 are known to hyperproliferative keratins. Lack of these keratins is consistent with a clinical indolent course of PCAC (20).

Our findings are consistent with previous research in the literature which showed that PCAC is negative for $\alpha$-SMA (smooth muscle actin), a useful marker of myoepithelial cells $(15,24)$. An ultrastructural study also found that PCAC, which displayed microvilli on the surface of the tumor cells under an electron microscope, showed differentiation into secretory cells $(14,25)$. Positivity for K7 and negativity for K1 and K14 was the same as in Miyamoto's previous report (5), but reactivity for K10 was different in our case, most likely due to the degree of tumor differentiation.

In conclusion, in our case, primary cutaneous apocrine carcinoma arose from secretory cells of ectopic apocrine glands within a congenital melanocytic nevus.

\section{References}

1. Pucevich B, Catinchi-Jaime S, Ho J and Lukic DM: Invasive primary ductal apocrine adenocarcinoma of axilla: a case report with immunohistochemical profiling and a review of literature. Dermatol Online J 14: 5, 2008.

2. Moll R, Franke WW, Schiller DL, Geiger B and Krepler R: The catalog of human cytokeratins: patterns of expression in normal epithelia, tumors and cultured cells. Cell 31: 11-24, 1982.
3. Schweizer J, Bowden PE, Coulombe PA, et al: New consensus nomenclature for mammalian keratins. J Cell Biol 174: 169-174, 2006.

4. Dale B and Ling SY: Immunologic cross-reaction of stratum corneum basic protein; a keratohyaline granule protein. J Invest Dermatol 72: 257-261, 1979.

5. Miyamoto T, Inoue S, Adachi K and Takada R: Differential expression of mucin core proteins and keratins in apocrine carcinoma, extramammary Paget's disease and apocrine nevus. J Cutan Pathol 36: 529-534, 2009.

6. Gown AM and Vogel AM: Monoclonal antibodies to intermediate filament proteins of human cells: unique and cross-reactivity antibodies. J Cell Biol 95: 414-424, 1992.

7. Lane EB, Bartek J, Purkis PE and Leigh IM: Keratin antigens in differentiating skin. Ann NY Acad Sci 455: 241-258, 1985.

8. Leigh I, Purkis PE, Whitehead P and Lane EB: Monospecific monoclonal antibodies to keratin 1 carboxyterminal (synthetic peptide) and to keratin 10 as markers of epithelial differentiation. Br J Dermatol 129: 110-119, 1993.

9. Jih DM, Lyle S, Elenitsas R, Elder DE and Cotsarelis G: Cytokeratin 15 expression in trichoepitheliomas and a subset of basal cell epitheliomas suggests they originate from hair follicle stem cells. J Cutan Pathol 26: 113-118, 1999.

10. Lindberg K and Rheinwald JG: Suprabasal 40 kd keratin (K19) expression as an immunohistologic marker of pregnancy in oral epithelium. Am J Pathol 134: 89-98, 1989.

11. Kurokawa I, Mizutani H, Kusumoto K, Nishijima S, Tsujita-Kyutoku M, Shikata N and Tsubura A: Cytokeratin, filaggrin and p63 expression in reepithelialization during human cutaneous wound healing. Wound Repair Regen 14: 38-45, 2006.

12. Requena L, Kiryu H and Ackerman AB: Ductal carcinoma. In: Neoplasms With Apocrine Differentiation. 1st edition. Lippincott-Raven, Philadelphia, pp607-649, 1998.

13. Shintaku M, Tsuta K, Yoshida H, Tsubura A, Nakashima Y and Noda K: Apocrine adenocarcinoma of the eyelid with aggressive biological behavior: report of a case. Pathol Int 52: 169-173, 2002.

14. Katagiri Y and Ansai S: Two cases of cutaneous apocrine ductal carcinoma of the axilla. Dermatology 199: 332-337, 1999.

15. Hayes MM, Matisic JP and Weir L: Apocrine carcinoma of the lip: a case report including immunohistochemical and ultrastructural study, discussion of differential diagnosis and review of the literature. Oral Surg Oral Med Oral Pathol Oral Radiol Endod 82: 193-199, 1996

16. Dalle S, Skowron F, Balme B and Perrot H: Apocrine carcinoma developed in nevus sebaceous of Jadassohn. Eur J Dermatol 13: 487-489, 2003.

17. Hugel H and Requena L: Ductal carcinoma arising from a syringocystadenoma papilliferum in a nevus sebaceous of Jadassohn. Am J Dermatopathol 25: 490-493, 2003.

18. Miyamoto T, Hagari $\mathrm{Y}$, Inoue $\mathrm{S}$, Watanabe $\mathrm{T}$ and Yoshino $\mathrm{T}$ : Axillary apocrine carcinoma with benign apocrine tumours: a case report involving a pathological and immunohistochemical study and review of the literature. J Clin Pathol 58: 757-761, 2005.

19. Amo Y and Kawano N: A case of ductal apocrine carcinoma in the left axilla with tubular apocrine adenoma in the right axilla. J Dermatol 30: 72-75, 2003.

20. Paties C, Taccagni GL, Papotti M, Valente G, Zangrandi A and Aloi F: Apocrine carcinoma of the skin. A clinicopathologic, immunocytochemical, and ultrastructural study. Cancer 71: 375-381, 1993.

21. Tsujino Y and Dekio S: Apocrine carcinoma: a report of a case which formed a single tumor with eccrine spiradenoma. Skin Cancer (in Japanese) 17: 98-100, 2002.

22. Kurokawa I, Urakawa Y, Senba Y, et al: Keratin profiles may differ between intraepidermal and intradermal invasive eccrine porocarcinoma. Oncol Rep 16: 473-477, 2006.

23. Ishida-Yamamoto A, Iizuka $\mathrm{H}$ and Eady RA: Filaggrin immunoreactive composite keratohyalin granules specific to acrosyringia and related tumours. Acta Derm Venereol 74: 37-42, 1999.

24. Castelli E, Wollina U, Anzarone A, Morello V and Tomasino RM: Extramammary Paget disease of the axilla associated with comedo-like apocrine carcinoma in situ. Am J Dermatopathol 24: 351-357, 2002.

25. Yamamoto O, Haratake J, Hisaoka M, Asahi M and Bhawan J: A unique case of apocrine carcinoma on the male pubic skin: histopathologic and ultrastructural observations. J Cutan Pathol 20: 378-383, 1993. 